\title{
Analysis of the ozone profile specifications in the WRF-ARW model and their impact on the simulation of direct solar radiation
}

\author{
A. Montornès ${ }^{1,2}$, B. Codina ${ }^{1}$, and J. W. Zack ${ }^{3}$ \\ ${ }^{1}$ Department of Astronomy and Meteorology, University of Barcelona, Barcelona, Spain \\ ${ }^{2}$ Information Services, AWS Truepower, Barcelona, Spain \\ ${ }^{3}$ MESO Inc., Troy, NY, USA \\ Correspondence to: A. Montornès (amontornes@am.ub.es)
}

Received: 21 February 2014 - Published in Atmos. Chem. Phys. Discuss.: 6 August 2014

Revised: 16 December 2014 - Accepted: 19 January 2015 - Published: 10 March 2015

\begin{abstract}
Although ozone is an atmospheric gas with high spatial and temporal variability, mesoscale numerical weather prediction (NWP) models simplify the specification of ozone concentrations used in their shortwave schemes by using a few ozone profiles. In this paper, a two-part study is presented: (i) an evaluation of the quality of the ozone profiles provided for use with the shortwave schemes in the Advanced Research version of the Weather Research and Forecasting (WRF-ARW) model and (ii) an assessment of the impact of deficiencies in those profiles on the performance of model simulations of direct solar radiation. The first part compares simplified data sets used to specify the total ozone column in six schemes (i.e., Goddard, New Goddard, RRTMG, CAM, GFDL and Fu-Liou-Gu) with the Multi-Sensor Reanalysis data set during the period 19792008 examining the latitudinal, longitudinal and seasonal limitations in the ozone profile specifications of each parameterization. The results indicate that the maximum deviations are over the poles and show prominent longitudinal patterns in the departures due to the lack of representation of the patterns associated with the Brewer-Dobson circulation and the quasi-stationary features forced by the land-sea distribution, respectively. In the second part, the bias in the simulated direct solar radiation due to these deviations from the simplified spatial and temporal representation of the ozone distribution is analyzed for the New Goddard and CAM schemes using the Beer-Lambert-Bouguer law and for the GFDL using empirical equations. For radiative applications those simplifications introduce spatial and temporal biases with near-zero departures over the tropics throughout the year and increas-
\end{abstract}

ing poleward with a maximum in the high middle latitudes during the winter of each hemisphere.

\section{Introduction}

The impact of the ozone variations in mesoscale numerical weather prediction (NWP) models has historically not been treated as a significant issue (Dudhia, 2014). This is primarily related to two factors. First, these models are not designed for stratosphere simulations because the typical timescales of mesoscale processes differ from the timescales of the interaction between the stratosphere and the troposphere. Second, the errors introduced into the solar irradiation by not considering ozone variations are typically much smaller than other sources of error such as those associated to the cloud distribution.

There is a growing interest in new applications of the mesoscale NWP models such as solar energy modeling (e.g., Ruiz-Arias et al., 2013) that require an accurate treatment of the radiative transfer equation (RTE) throughout the entire atmosphere as well as for the study of the stratosphere (e.g., Kim and Wang, 2011) that needs an accurate computation of the solar heating rate.

Together with water vapor, ozone is the most important absorber of the solar radiation in the Earth's atmosphere in cloudless and clear (i.e., without aerosols) sky conditions.

This gas is located in two atmospheric regions with a different impact on the radiative transfer (WMO, 2011). Most ozone $(\sim 90 \%)$ is located in the stratosphere. A layer with the highest ozone concentration that is typically found be- 
tween 10 and $50 \mathrm{~km}$ above the surface is often referred to as the ozone layer. The remaining ozone $(\sim 10 \%)$ is found in the troposphere. The highest values in this layer are located near the surface and they are mainly related to human activities.

The absorption by ozone in the solar spectral region occurs in three spectral bands: Hartley, Huggins and Chappuis (Inn and Tanaka, 1953; Anderson and Mauersberger, 1992). The Hartley bands are the strongest covering the ultraviolet (UV) from 200 to $300 \mathrm{~nm}$. This absorption of solar flux is located primarily in the upper stratosphere and in the mesosphere. The other two bands are weaker. The Huggins bands operate in a UV region from 300 to $360 \mathrm{~nm}$. Energy absorption in this spectral range occurs in the lower stratosphere and in the troposphere. Finally, the Chappuis bands cover the photosynthetic active region (PAR) and the near-IR from 400 to $850 \mathrm{~nm}$. The absorption by the Chappuis bands is mainly located in the troposphere.

The absorption of the solar flux by ozone produces a heating rate ranging from 10 to $30 \mathrm{Kday}^{-1}$ in the stratosphere. This absorbed energy is an important physical process in maintaining the stratospheric thermal structure (Ramanathan and Dickinson, 1979).

Stratospheric ozone is continuously created and destroyed by photochemical processes associated with solar UV radiation. Due to the annual solar variation as well as the Earth's sphericity, significant latitudinal and seasonal variations on the ozone distribution are observed. Since the tropics receive more insolation than the poles, those processes result in an ozone source in the tropics and a net poleward transport due to the large-scale air circulation in the stratosphere referred to as the Brewer-Dobson circulation (Brewer, 1949; Dobson, 1956). Consequently, the ozone layer in the tropics is thinner than at middle and higher latitudes where ozone is accumulated, increasing the thickness and, thus, the total ozone amount.

Seasonally, the total ozone in the tropics shows smaller variations than in the polar regions. The total ozone is maximum at high latitudes after the polar night because the ozone transport due to the Brewer-Dobson circulation is maximum during late fall and winter. In contrast, this circulation is weaker during summer and early fall, more in the Southern Hemisphere than in the Northern Hemisphere. In the polar summer, when daylight is continuous, the total ozone decreases gradually reaching the lowest value in early fall. This process is known as ozone depletion. Nevertheless, in Antarctica, an important minimum is observed in spring (September-October) as a result of chemical ozone destruction by other substances (i.e., the ozone hole).

Mesoscale NWP models do not consider prognostic or diagnostic equations for the ozone gas and its photochemical processes. In order to reduce the computational resources, the shortwave schemes in mesoscale NWP models simplify the ozone information. These simplifications include zonal averages and latitudinal, vertical and seasonal discretization that vary between shortwave parameterizations.
In the past few years, there has been considerable interest in improving the ozone representation within the WRF-ARW model. The version 3.5 (available since 2013) included a new option to share the ozone data sets between two schemes (see Sect. 2.1).

This paper presents an analysis of the strategies that are employed to specify the ozone profiles used as input into the shortwave radiation schemes in the WRF-ARW model. The analysis is split into two parts: (i) a study of the simplifications assumed in the ozone profiles and (ii) an analysis of the uncertainties associated with the computation of the direct solar radiation. In both, the idea is to show a global perspective (spatial and seasonal) of the impact of simplified specifications of the ozone distribution on the radiative transfer computation in the current solar parameterizations.

In the first part, spatial and temporal deviations over the total ozone column are discussed. Each ozone profile provided with the WRF-ARW package is vertically integrated and compared with monthly averaged values from the MultiSensor Reanalysis (MSR) data set (van der A et al., 2010) during the climate period 1979-2008. Surface conditions for the vertical integration are based on the ERA-Interim ${ }^{1}$ reanalysis (Dee et al., 2011) for the same climate period.

In the second part, the effect of this error on the direct solar radiation at the surface is computed considering an atmosphere composed only of ozone. The analysis focuses on three shortwave schemes: the New Goddard (Chou and Suarez, 1999; Chou et al., 2001), the CAM (Collins et al., 2004) and the GFDL (Fels and Schwarzkopf, 1981). The first and second schemes use an ozone mass absorption coefficient that is independent of the temperature and pressure and consequently, the Beer-Lambert-Bouguer law may be computed as a function of the total ozone column calculated in the first part of the study. The GFDL scheme uses empirical equations as a function of the ozone amount that allows a similar treatment.

\section{Methodology}

\subsection{Ozone absorption in the WRF-ARW model}

Version 3.6.1 of the WRF-ARW model, available since 2014, includes seven shortwave schemes: Dudhia (available since 2000), Goddard (2000), New Goddard (2011), GFDL (2004), RRTMG (2009), CAM (2006) and FLG (2011).

The Dudhia scheme (Dudhia, 1989) is the simplest shortwave parameterization in the model without any consideration of the ozone absorption. For this reason, this parameterization is not considered in the following analyses.

The Goddard and the New Goddard schemes (Chou and Suarez, 1994, 1999; Chou et al., 2001) are similar because the second is an update of the first. The ozone treatment is

\footnotetext{
${ }^{1}$ ECMWF ERA-Interim data used in this study have been obtained from the ECMWF data server.
} 
common for both schemes and is based on Chou and Suarez (1999). Both schemes will subsequently be denoted as GNG. In these schemes the solar spectrum is divided into eleven spectral bands (seven in the ultraviolet, UV, one in the visible or photosynthetic active region, PAR, and three in the near-infrared, near-IR). In the UV+PAR spectral regions, G-NG neglect the pressure and temperature (i.e., height) dependence of the ozone absorption assuming a constant absorption coefficient in each spectral interval. These coefficients are obtained by dividing each band into 127 narrow sub-bands with a width of $\sim 0.003 \mu \mathrm{m}$ and using the ozone absorption coefficient given in WMO (1986). The absorption in the near-IR is added by enhancing the absorption in the PAR region, reducing the computational time. The New Goddard scheme introduces a small correction for the ozone absorption coefficient in the PAR region, from $0.0539(\mathrm{~cm}-$ atm) $\mathrm{stp}^{-1}$ to $0.0572(\mathrm{~cm}-\mathrm{atm}) \mathrm{stp}^{-1}$. The effect of this correction can be neglected for the purposes of this paper, which considers both schemes as one. All results are based on New Goddard values since it is the newest version.

The CAM scheme (Collins et al., 2004) splits the spectrum into nineteen bands (seven for the ozone, one in the visible or PAR, seven for the water vapor, three for the carbon dioxide and one for the near-IR). The ozone absorption is computed over the seven ozone bands and over the PAR region as well. As in the previous scheme, the CAM parameterization assumes a constant ozone absorption coefficient for each band. The procedure to compute these coefficients is described in Briegleb (1992).

The GFDL scheme (Fels and Schwarzkopf, 1981) divides the spectrum in two spectral bands: one in the UV+PAR and the other in the near-IR (composed by different subdivisions). The ozone absorption occurs in the UV+PAR region following the parametric formulas described in Lacis and Hansen (1974). It is noteworthy that it is the only scheme that considers the light scattering due to the ozone, explicitly. However, due to the small contribution it is not considered for the purposes of this paper.

The RRTMG (Iacono et al., 2008) parameterization divides the shortwave spectrum into fourteen bands covering the UV, PAR and near-IR regions. Each spectral band is divided in a set of sub-intervals (i.e., quadrature points) used to integrate the k-distributions for the correlated k-distribution (CKD) method detailed in Liou (1980) and Fu and Liou (1992). This scheme takes into account the ozone absorption coefficient dependence on pressure and temperature for each spectral band and interval. These values are stored in an external file called RRTMG_SW_DATA.

The Fu-Liou-Gu scheme (Fu and Liou, 1992; Gu et al., 2011) splits the solar spectrum into six spectral bands. As in the RRTMG parameterization, the interaction with the absorber gases is based on the CKD method.

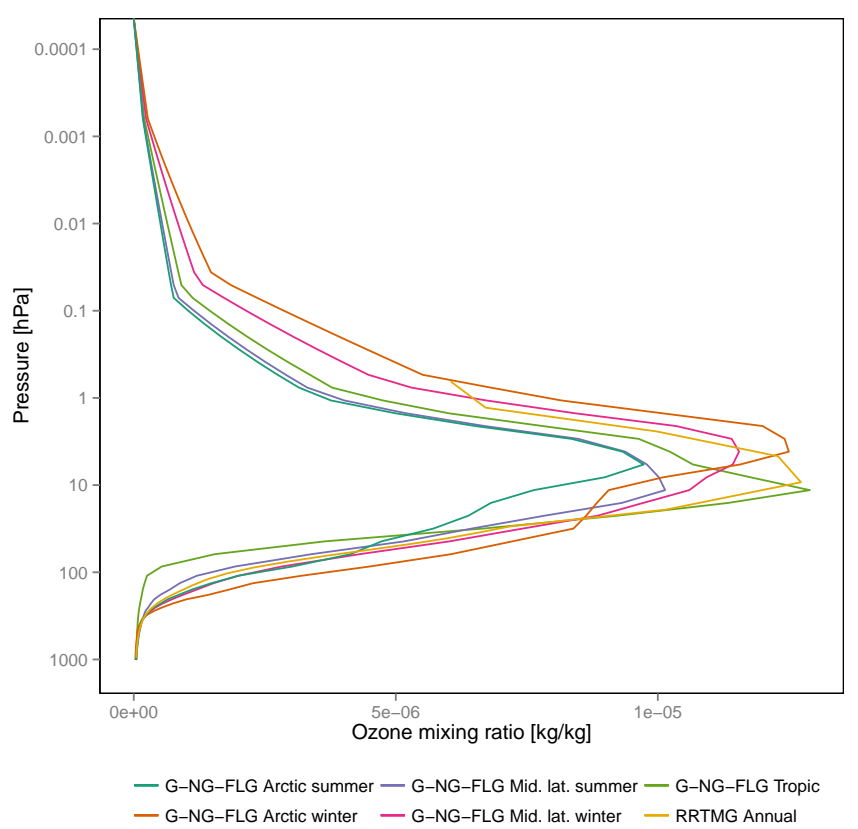

Figure 1. Ozone profile data sets available in the G-NG-FLG and RRTMG parameterizations.

Each aforementioned shortwave scheme has available different data sets reproducing ozone mixing ratio conditions in the atmosphere as a function of the pressure (i.e., vertical profile), the latitude and the season. The complexity of these data sets varies from one scheme to the other as it is summarized in Table 1 and illustrated in Figs. 1, 2 and 3. When a shortwave scheme is called by the model, the profiles are selected and interpolated into the sigma levels defined in the simulation domain.

G-NG and FLG schemes include five ozone profiles based on the same data sets (Fig. 1). These profiles simulate the ozone data for tropical, mid-latitude (summer/winter) and Arctic (summer/winter) atmospheres. The selection of a profile for use in the computations is based on the latitude of the center of the domain as well as on the day of the year. Tropical regions are assumed between $30^{\circ} \mathrm{S}$ and $30^{\circ} \mathrm{N}$ without seasonal variation. In this profile, the ozone mixing ratio is maximum at $11.417 \mathrm{hPa}$ with a peak of $1.29 \times 10^{-5} \mathrm{~kg} \mathrm{~kg}^{-1}$. Mid-latitudes and Arctic regions are defined between 30 60 and $60-90^{\circ}$, respectively, considering winter and summer variations. In the Northern Hemisphere, winter is assumed between the 285th and the 80th days of the year and summer between the 81 st and the 284th day of the year. In the Southern Hemisphere the dates associated with the winter and summer periods are reversed. The ozone layer in midlatitudes and Arctic regions has a lower ozone concentration than in the tropics and is found at a lower altitude in summer than in winter. The highest level for all these profiles is set at $0.0006244 \mathrm{hPa}$ while surface conditions depend on 
Table 1. Description of the ozone profiles in the shortwave schemes in the WRF-ARW model. The Dudhia scheme is not analyzed in this study for reasons mentioned in the text.

\begin{tabular}{lrrlcl}
\hline Scheme & Profiles & Latitudes & Time & Levels & Location in code \\
\hline Dudhia & None & - & - & - & - \\
Goddard & 5 & 3 & Summer/winter & 75 & Subroutine gsfcswrad in module_ra_gsfcsw.F \\
New Goddard & 5 & 3 & Summer/winter & 75 & Subroutine goddardrad in module_ra_goddard.F \\
GFDL & 148 & 37 & 4 seasons & 81 & Subroutine o3clim in module_ra_gfdl.F \\
RRTMG & 1 & 1 & Annual & 31 & Subroutine o3data in module_ra_rrtmg_lw.F \\
CAM & 768 & 64 & 12 months & 59 & Auxiliary file ozone.formatted \\
FLG & 5 & 3 & Summer/winter & 75 & Subroutine o3prof in module_ra_flg.F \\
\hline
\end{tabular}

the location and the season. In Sect. 3.1, they are referred as G-NG-FLG.

GFDL parameterization considers latitudinal and time variations based on the Eta/NMM model. Data sets are stored in a subroutine named O3CLIM. This routine generates a seasonal and spatial distribution considering four seasons (winter, spring, summer and fall) and $5^{\circ}$ latitudinal distribution (Fig. 2). Ozone profiles are allocated at 81 vertical levels from 1013.25 to $0.0094 \mathrm{hPa}$. These data sets are interpolated to each grid-point of the user-defined domain. The interpolation is performed in a subroutine named as OZON2D considering the latitude and the day of the year. These data sets show a north-south symmetry between seasons with small differences that can not be appreciated in Fig. 2. Ozone in tropical regions is practically constant in all seasons while the higher latitudes experience substantial temporal variability.

The RRTMG scheme includes two ozone profiles as a function of the season (winter or summer). Nevertheless, this granularity is useless due to the fact that the final used profile is computed as a composition of both, without considering the day of the year. Therefore, only one profile is assumed for any latitude and season (Fig. 1). Details about this simplification can be found in subroutine O3DATA of module_ra_rrtmg_lw.F. The highest level is located at $0.647 \mathrm{hPa}$. In the region between $\sim 50 \mathrm{hPa}$ and $\sim 10 \mathrm{hPa}$, this profile is similar to the G-NG-FLG tropical. Below $\sim 50 \mathrm{hPa}$, this profile is practically the same as G-NG-FLG at mid-latitudes while above $\sim 10 \mathrm{hPa}$ it is similar to G-NG-FLG at midlatitude and Arctic in winter. Since version 3.5, this scheme can utilize the ozone profiles available in the CAM scheme with the option o3input in the namelist.input file.

Finally, the CAM scheme includes several ozone profiles loaded from a binary auxiliary file called ozone_formatted with the ozone data and another two named ozone_lat.formatted and ozone_plev.formatted including latitude and pressure values, respectively. This data set covers 64 latitudes with a resolution $\sim 2.28^{\circ}$ and 59 pressure levels from 1003 to $0.28 \mathrm{hPa}$ for each month of the year (Fig. 3). These data sets show the highest variations in time and latitude without north-south symmetries as in
GFDL's profiles. Ozone values are latitudinally interpolated for each node of the domain.

Note that with the exception of CAM, all the ozone data sets show a bad representation of the ozone depletion in Antarctica throughout winter. This simplification will lead to large errors in this region as we will discuss in Sect. 3.

\subsection{Part one: study of the simplifications assumed in the ozone profiles}

In this part, ozone profiles of each shortwave parameterization are vertically integrated. Next, they are distributed over a regular $1^{\circ}$ per $1^{\circ}$ global domain for each month of a typical year using a bilineal interpolation. Then, these values are compared with the baseline typical year.

The reason to analyze the integrated profiles is the data availability because the real ozone profiles are limited in space and time. In general, these data sets are provided by ozone sounding stations located in a few sites around the world. Other data sets as the Binary Data Base of Profiles (Bodeker and Hassler, 2012) provide latitude and time variation profiles but neglect the longitudinal dependence and their values are the result of a regression model that fits real data. In contrast, satellite data provide a global covering but generally their algorithms compute the integrated amount.

First, let us assume one shortwave scheme. Given a vertical profile for the ozone mixing ratio called $q_{\mathrm{O}_{3}}(z)$, the total ozone column $\mathrm{TO}_{3}$, from the ground to the top of the atmosphere (TOA), is defined as

$T \mathrm{O}_{3}=\int_{0}^{\infty} \rho q_{\mathrm{O}_{3}} \mathrm{~d} z$,

where $\rho$ is the dry air density and $z$ is the height with respect to the ground.

Under the assumption of a well-stratified atmosphere, the pressure and the geometric height are related by the hydrostatic equation given by

$\mathrm{d} p=-\rho g \mathrm{~d} z$,

where $g$ is the gravity acceleration, assumed as a constant value. 
The hydrostatic equilibrium given by Eq. (2) leads Eq. (1) to

$$
T \mathrm{O}_{3}=\frac{1}{g} \int_{0}^{p_{\mathrm{s}}} q_{\mathrm{O}_{3}}(p) \mathrm{d} p .
$$

where pressure at TOA is zero by definition and the surface pressure is denoted by $p_{\mathrm{s}}$.

Note that the integration covers the entire atmosphere including the upper levels (i.e., above $86 \mathrm{~km}$ ) where the assumption of hydrostatic equilibrium progressively becomes less valid because the diffusion and vertical transport of the individual gas species become more important. In this context, the approach used in Eq. (3) is not valid leading to the need of a dynamically oriented model including the diffuse separation as shown in NOAA (1976). Notwithstanding, the dry air density and the ozone mixing ratio in those layers have an order of magnitude of $10^{-6} \mathrm{~kg} \mathrm{~m}^{-3}$ and $10^{-6} \mathrm{~kg} \mathrm{~kg}^{-1}$, respectively, and are monotonically decreasing. Hence, non-hydrostatic effects may be neglected for the purposes of the current analysis.

Because the available ozone profiles in the shortwave schemes are not analytical functions, Eq. (3) in practice must be solved using a numerical integration scheme such as Simpson's method. Further, for an ozone profile composed by $N$ vertical levels, Eq. (3) may be discretized such as

$$
\begin{aligned}
& T \mathrm{O}_{3}=\frac{1}{6 g} \sum_{k=1}^{N-1}\left(p_{k}-p_{k+1}\right)\left(q_{\mathrm{O}_{3}, k}+0.5\left(q_{\mathrm{O}_{3}, k}\right.\right. \\
& \left.\left.+q_{\mathrm{O}_{3}, k+1}\right)+q_{\mathrm{O}_{3}, k+1}\right),
\end{aligned}
$$

where $q_{\mathrm{O}_{3}, k}$ and $p_{k}$ are the ozone mixing ratio and the pressure at a level $k$.

This vertical integration requires two boundary conditions: the ozone mixing ratio at the TOA and the surface pressure. The first one is assumed as zero (i.e., without ozone between the last available level and the TOA). The surface pressure requires a complex treatment since it varies by location and season. This boundary condition is computed using the ERAInterim reanalysis covering the climate period from 1979 until 2008 (i.e., 30 years). This period is not arbitrary since it is consistent with the baseline data described below. Based on this period, monthly surface pressure averages are computed and used as surface conditions for the vertical integration of the ozone profiles.

From this procedure, the total ozone column for any location of the world and season can be computed. To quantify the geographical distribution of the errors, a global $1^{\circ}$ per $1^{\circ}$ grid is built using the latitudinal thresholds fixed in each shortwave scheme as described in Sect. 2.1. In order to examine the seasonal variability, values are computed throughout the twelve months of a year. Ozone profiles in some shortwave schemes like the New Goddard or the FLG are defined as a function of the day of the year instead of the month. In this situation, months are identified by the 15th day of the month. This means that January is the 15 th day of the year, February is the 46th day of the year, etc.

These gridded results are compared with real data. The ozone data used as a baseline were derived from the MultiSensor Reanalysis, MSR (van der A et al., 2010), during the period 1979-2008 and are monthly averaged (this data set is provided with a monthly resolution).

The MSR was created from all available ozone column data measured by fourteen polar orbiting satellites in the near-ultraviolet Huggins band from November 1978 to December 2008, including TOMS (on the satellites Nimbus-7 and Earth Probe), SBUV (Nimbus-7, NOAA-9, NOAA-11 and NOAA-16), GOME (ERS-2), SCIAMACHY (Envisat), OMI (EOS-Aura), and GOME-2 (Metop-A). The data set processing includes two steps. In the first one, a bias correction scheme is applied over all satellite observations based on independent ground-based total ozone data from the World Ozone and Ultraviolet Data Center. In the second step, a data assimilation process is applied using a sub-optimal implementation of the Kalman filter method and based on a chemical transport model driven by ECMWF meteorological fields. This data set shows a bias departure less than $1 \%$ with a root mean square standard deviation of around $2 \%$ as compared to the corrected satellite observations used.

Therefore, for each node $i$ (west-east direction) and $j$ (south-north direction) and, month $m$, we have two data sets: one for each model under consideration, $\mathrm{TO}_{3, \text { sch, } i j}(m)$, and the other describing the baseline data, $T \mathrm{O}_{3}, \mathrm{MSR}, i j(m)$. Both data sets may be compared node by node for the entire typical year. We define the relative error of the parameterization $\epsilon_{i j}(m)$ as

$\epsilon_{\text {sch }, i j}(m)=T \mathrm{O}_{3, \text { sch, }, i j}(m)-T \mathrm{O}_{3, \operatorname{MSR}, i j}(m)$.

This metric will be used to analyze the spatial and temporal patterns of the deficiencies in the simplified profiles of ozone used by the shortwave schemes.

\subsection{Part two: an analysis of the uncertainties added to the computation of the direct solar radiation}

In the second part of the study, the previously computed total ozone columns are used to examine the ozone absorption over the direct solar radiation and to determine the introduced bias based on climate patterns.

Given one spectral band, the downward flux $F_{\lambda}^{\downarrow}$ can be divided in two components: the direct $F_{\lambda \text {, dir }}^{\downarrow}$ and the diffuse $F_{\lambda, \text { dif }}^{\downarrow}$ as

$F_{\lambda}^{\downarrow}=F_{\lambda, \mathrm{dir}}^{\downarrow}+F_{\lambda, \mathrm{dif}}^{\downarrow}$.

Each component requires a different mathematical treatment.

Considering a direct light beam from the Sun, traveling throughout a non-scattering isotropic plane-parallel at- 
mosphere, the monochromatic downward solar flux density, covering the spectral interval $\Delta \lambda$, may be written as

$F_{\lambda, \operatorname{dir}}^{\downarrow}\left(\tau_{\lambda}\right)=\mu_{0} F_{0}(\lambda) e^{-\tau_{\lambda} / \mu_{0}}$,

where $\tau_{\lambda}$ is denoted as the optical thickness for the spectral band $\lambda$ and $\mu_{0}$ is the cosine of the solar zenith angle. The derivation of Eq. (7) is extensively discussed in the literature such as in Chandrasekhar (1960) or in Liou (1980). This expression is commonly denoted as the Beer-LambertBouguer law.

In contrast, the diffuse component requires solving the RTE in terms of a set of radiative variables as the optical thickness, the single scattering albedo and the asymmetry factor. Nevertheless, the common approximation in the solar parameterizations is to assume the ozone contribution in the Rayleigh scattering term. This term is computed as a function of the air mass without any consideration of the gas species. Therefore, the diffuse flux does not depend on the ozone data and is not analyzed in this paper.

In a non-scattering medium, when a solar beam travels throughout a layer, one part of the energy is absorbed $A_{\lambda}$ by the medium and the other part is transmitted $T_{\lambda}$ to the next layer (i.e., energy conservation). In other words, if we consider normalized values

$1=A_{\lambda}+T_{\lambda}$.

As described in Liou (1980), due to the structure of the absorption lines, it is required to define the monochromatic absorptance covering the interval $\Delta \lambda$ as

$A_{\bar{\lambda}}\left(\tau / \mu_{0}\right)=\int_{\Delta \lambda}\left(1-e^{-\tau_{\lambda} / \mu_{0}}\right) \frac{\mathrm{d} \lambda}{\Delta \lambda}$.

Then, assuming that the solar flux variation is small in $\Delta \lambda$, Eqs. (7) and (9) lead to

$F_{\bar{\lambda}, \operatorname{dir}}^{\downarrow}\left(\tau / \mu_{0}\right) \cong \mu_{0} F_{0}(\lambda)\left(1-A_{\bar{\lambda}}\left(\tau / \mu_{0}\right)\right)$.

Integrating Eq. (10) over the entire solar spectrum, the total flux $F_{\text {dir }}^{\downarrow}\left(\tau / \mu_{0}\right)$ may be expressed as

$F_{\text {dir }}^{\downarrow}\left(\tau / \mu_{0}\right)=\int_{0}^{\infty} \mu_{0} F_{0}(\lambda)\left(1-A_{\bar{\lambda}}\left(\tau / \mu_{0}\right)\right) \mathrm{d} \lambda$.

Trivially, the radiation received at the TOA may be written as

$\mu_{0} F_{0}=\int_{0}^{\infty} \mu_{0} F_{0}(\lambda) \mathrm{d} \lambda$.

Thus, Eq. (11) may be expressed as

$F_{\text {dir }}^{\downarrow}\left(\tau / \mu_{0}\right)=\mu_{0} F_{0} \int_{0}^{\infty} W(\lambda)\left(1-A_{\bar{\lambda}}\left(\tau / \mu_{0}\right)\right) \mathrm{d} \lambda$, where $W(\lambda)$ is the ratio of the extraterrestrial energy in a band $\mathrm{d} \lambda$ as

$W(\lambda)=\frac{F_{0}(\lambda)}{F_{0}}$.

Defining the total absorption $A\left(\tau / \mu_{0}\right)$ as

$A\left(\tau / \mu_{0}\right)=\mu_{0} F_{0} \int_{0}^{\infty} W(\lambda) A_{\bar{\lambda}}\left(\tau / \mu_{0}\right) \mathrm{d} \lambda$,

Eq. (13) may be written as

$F_{\text {dir }}^{\downarrow}\left(\tau / \mu_{0}\right)=\mu_{0} F_{0}-A\left(\tau / \mu_{0}\right)$.

Let us now consider the particular case in which the dependence of the optical thickness on wavelength in the interval $\Delta \lambda$ can be neglected. In that case, Eq. (9) may be written as

$A_{\bar{\lambda}}\left(\tau / \mu_{0}\right)=1-e^{-\tau_{\lambda} / \mu_{0}}$.

Leading Eq. (11) to

$F_{\text {dir }}^{\downarrow}\left(\tau / \mu_{0}\right)=\mu_{0} F_{0} \int_{0}^{\infty} W(\lambda) e^{-\tau_{\lambda} / \mu_{0}} \mathrm{~d} \lambda$.

Therefore, from Eqs. (16) and (18), the total absorption can be isolated and computed as

$A\left(\tau / \mu_{0}\right)=\mu_{0} F_{0}-\mu_{0} F_{0} \int_{0}^{\infty} W(\lambda) e^{-\tau_{\lambda} / \mu_{0}} \mathrm{~d} \lambda$.

The optical thickness is a function of the gases and particles that compose the atmosphere and of the absorption coefficient cross section of each one. A widely used approximation is to assume that a set of absorbers are independent of one another. Therefore, the radiative schemes compute the total optical thickness $\tau_{\lambda}$ as the sum of different contributions such as ozone $\tau_{\lambda, O_{3}}$, water vapor $\tau_{\lambda \text {,wv }}$, clouds $\tau_{\lambda \text {,cld }}$, aerosols $\tau_{\lambda \text {,aer }}$ and others:

$\tau_{\lambda}=\tau_{\lambda, \mathrm{O}_{3}}+\tau_{\lambda, \mathrm{wv}}+\tau_{\lambda, \mathrm{cld}}+\tau_{\lambda, \text { aer }}+\ldots$

Thus, considering Eq. (20), the contribution of each absorber to the absorption can be analyzed independently in Eq. (19).

In the particular case of the ozone, the optical thickness defined from the TOA to a level $z$ may be expressed as

$\tau_{\lambda, \mathrm{O}_{3}}(z)=\int_{z}^{\infty} k_{\lambda} \rho q_{\mathrm{O}_{3}} \mathrm{~d} z$,

where $k_{\lambda}$ denotes the mass absorption cross section and $\rho$ is the dry air density. Note that this integral requires the vertical information of the ozone mixing ratio and the dry air density. 
Moreover, $k_{\lambda}$ is dependent on temperature and pressure as can be demonstrated by virtue of the kinetic theory of gases. Hence, as $\tau_{\lambda, \mathrm{O}_{3}}$ is a function of the height $z$ and this is a function of the temperature and pressure, the integral can not be computed without detailed information about $k_{\lambda}$.

Regarding the spectral computation given by Eq. (19), the most accurate method is the line-by-line (LBL) calculation. However, this method is not computationally feasible because it would require many thousands of computations at each grid-point. Instead of this, some approximations are assumed in terms of the gas and its spectral behavior.

Ozone absorption coefficient cross section shows a smooth variation with the wavelength (Inn and Tanaka, 1953). Hence, an effective $k_{\lambda}$ is defined for each spectral band. This coefficient is previously computed using the LBL at a reference pressure and temperature and then, scaled to the pressure and temperature of each value in order to consider the dependency on these magnitudes.

Goddard, New Goddard and CAM follow this approach without scaling $k_{\lambda}$ as detailed in Chou and Suarez (1999) and Briegleb (1992).

Thus, the absorption coefficient becomes temperature and pressure independent and Eq. (21) may be expressed by

$\tau_{\lambda, \mathrm{O}_{3}}(z)=k_{\lambda} \int_{z}^{\infty} \rho q_{\mathrm{O}_{3}} \mathrm{~d} z$.

Extending the integral over the entire atmosphere and assuming the hydrostatic equilibrium given by Eq. (2), Eq. (22) may be written as

$\tau_{\lambda, \mathrm{O}_{3}}\left(p_{\mathrm{s}}\right)=\frac{k_{\lambda}}{g} \int_{0}^{p_{\mathrm{s}}} q_{\mathrm{O}_{3}} \mathrm{~d} p$.

In virtue of Eq. (3), the optical thickness may be expressed as

$\tau_{\lambda, \mathrm{O}_{3}}\left(p_{\mathrm{s}}\right)=\frac{k_{\lambda}}{g} T \mathrm{O}_{3}\left(p_{\mathrm{s}}\right)$.

Substituting Eq. (24) into Eq. (19), the total absorption may be written as

$A\left(\tau_{\lambda, \mathrm{O}_{3}} / \mu_{0}\right)=\mu_{0} F_{0}\left(1-\int_{0}^{\infty} W(\lambda) e^{-\frac{k \lambda}{g \mu_{0}} T \mathrm{O}_{3}} \mathrm{~d} \lambda\right)$.

The necessary information to compute the $A\left(\tau / \mu_{0}\right)$ in Eq. (25) are the $\mathrm{TO}_{3}, W(\lambda), k_{\lambda}$, and $\mu_{0}$. Information about the $\mathrm{TO}_{3}$ can be obtained from Sect. 2.2. The $W(\lambda), k_{\lambda}$ are data available in the source code of each shortwave scheme (i.e., New Goddard and CAM). Finally, the cosine of the solar zenith angle $\mu_{0}$ may be computed as a function of the latitude, the longitude, the hour, and the day of the year.

From the expression (25), we can conclude that, given a fixed wavelength, there are two variables that may change the ozone absorption over the globe. The first is the cosine of the solar zenith angle which determines the length of a solar beam's path through the atmosphere. The beam traverses a longer path when the Sun is near the horizon than when it is higher in the sky. The second is the total ozone column which modulates the opacity of the atmosphere. Higher opacity results in more absorption and less transmission of radiative energy.

Regarding RRTMG and FLG, both consider the absorption coefficient dependence on pressure and temperature as we explained in Sect. 2. Therefore, the approximation assumed in Eq. (22) is not valid. For this reason these schemes are not considered in the Part two.

The aforementioned procedure can not be applied to GFDL because this scheme does not calculate Beer's law explicitly. Instead of that, this scheme uses empirical relationships proposed by Lacis and Hansen (1974). Following these expressions, the ozone absorption is computed as

$A_{\mathrm{O}_{3}}^{u v}(x)=\frac{1.082 x}{(1+138.6 x)^{0.805}}+\frac{0.0658 x}{1+(103.6 x)^{3}}$

in the UV spectral region, and

$A_{\mathrm{O}_{3}}^{\mathrm{vis}}(x)=\frac{0.02118 x}{1+0.042 x+0.000323 x^{2}}$

in the PAR region.

In Eqs. (26) and (27), $x$ is defined as the ozone amount $u_{\mathrm{O}_{3}}$ traversed by the solar beam in a defined layer as

$x=u_{\mathrm{O}_{3}} M$,

where $M$ is the magnification factor proposed by Rodgers (1979) as

$M=\frac{135}{\left(1224 \mu_{0}^{2}+1\right)^{1 / 2}}$.

Therefore, considering the UV and PAR bands as a single one, the total absorption is

$A(x)=A_{\mathrm{O}_{3}}^{u v}(x)+A_{\mathrm{O}_{3}}^{\mathrm{par}}(x)$.

Note that if we integrate the layer values (i.e., $u_{\mathrm{O}_{3}}$ ) over the entire atmosphere, the result is $\mathrm{TO}_{3}$ as in schemes New Goddard and CAM. Thus, although this parameterization does not compute Beer's law, an analogous procedure can be applied.

Under these considerations, given a shortwave scheme, Eq. $(25)^{2}$ is applied over each node of the grid for all months. To calculate the bias, the absorption is computed using $\mathrm{TO}_{3}$ from the model and MSR data sets. For a given month $m$, let us assume $A_{\text {sch }}(i, j)(m)$ and $A_{\mathrm{MSR}}(i, j)(m)$ the absorption

\footnotetext{
${ }^{2}$ Eq. (30) in GFDL.
} 
result for the ozone data set of the scheme and the MSR, respectively, for a node at $i$ (west-east direction) and $j$ (southnorth direction). The bias of the parameterization $\operatorname{BIAS}_{i j}(m)$ may be defined as

$$
\operatorname{BIAS}_{i j}(m)=A_{\text {sch }, i j}(m)-A_{\mathrm{MSR}, i j}(m) .
$$

To avoid day/night problems throughout the zonal direction, all longitudes assume midday in local time (i.e., the minimum slant path). In the meridional direction, those latitudes showing a solar zenith angle greater than $80^{\circ}$ are considered as night (i.e., polar night).

Considering Eq. (8), an overestimation (underestimation) in the ozone absorption implies that the modeled atmosphere is too opaque (transparent) and consequently, the direct flux is underestimated (overestimated) in the same magnitude with an opposite sign.

\section{Results}

\subsection{Part one: study of the simplifications assumed in the ozone profiles}

The results of the evaluation of the ozone profiles provided with the WRF-ARW model using the procedures description in Sect. 2.2 are presented in this section. We first focus on detailing results for each data set (i.e., RRTMG, G-NG-FLG, CAM and GFDL) over the globe. After this, there is a general discussion of the spatial and temporal deviation patterns.

In the RRTMG scheme, shown in Fig. 4, the lowest deviations of the total ozone column are observed along the mid-latitudes of each hemisphere during the respective (i.e., Northern or Southern Hemisphere) winter and spring, lower in the Northern than in the Southern. The global minimum is reached in May, in Siberia ( -30 DU) and across Europe (between -20 and $+20 \mathrm{DU})$. With the exception of the ozone hole, the largest departures in the total ozone column are observed along the tropics $(+100$ to $+150 \mathrm{DU})$ as a function of the month. An asymmetry with respect to the Equator line is observed, reaching the highest overestimation in the winter hemisphere due to the low ozone production. The global maximum is observed over Antarctica in September $(+170$ to $+190 \mathrm{DU})$ and October $(+180$ to $+200 \mathrm{DU})$.

The G-NG-FGL results, Fig. 5, show a strong difference between the tropics, mid-latitudes and high latitudes. The tropics show the best accuracy over the year with values between -20 and $+20 \mathrm{DU}$ with a tendency to underestimate the total ozone column values. Seasonally, positive and negative departures are observed over the summer and winter hemispheres, respectively. Mid-latitudes and high latitudes show a high seasonal variability due to the ozone profiles being limited to winter or summer (Table 1). The mid-latitude winter profile shows positive deviations over both hemispheres, larger in the Southern Hemisphere from March to May $(+40$ to $+120 \mathrm{DU})$ and lower in the Northern Hemi-
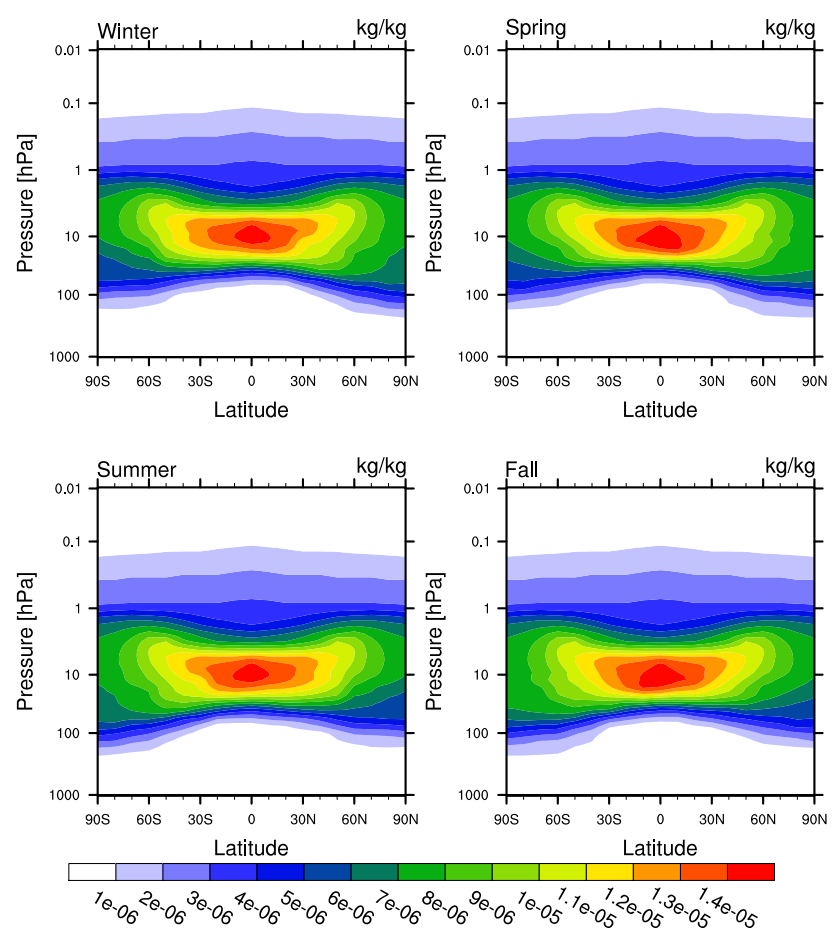

Figure 2. Ozone profile data sets available in GFDL.

sphere from December to February ( -60 to -0 DU over the eastern side of Asia, -20 to $0 \mathrm{DU}$ over the northern side of the United States and 0 to +100 DU over the rest). In January a near-zero belt around $60^{\circ} \mathrm{N}$ is observed, which expands southward during February and March. In contrast, the mid-latitude summer profile drifts from slightly negative departures during the spring to slightly positive deviations in summer of each hemisphere. The Arctic winter profile shows positive deviations in both hemispheres. The greatest values in the Northern Hemisphere are observed in October (around +200 DU in Greenland and the Scandinavian Peninsula) while the largest deviations in the Southern Hemisphere are reached in September $(+260$ to +300 DU over Antarctica). The Arctic summer profile shows different patterns in each hemisphere. In the Northern Hemisphere, negative deviations $(-80$ to $-20 \mathrm{DU})$ are observed during the spring drifting into positive departures in summer $(+20$ to $+40 \mathrm{DU}$ in July, +40 to $+80 \mathrm{DU}$ in August and +60 to $+80 \mathrm{DU}$ in September) with near-zero values in June. The Southern Hemisphere shows positive departures during all the months, reaching the minimum value in December in Antarctica $(+20$ to $+60 \mathrm{DU}$ ).

In the CAM case, Fig. 6, the latitudinal and seasonal variations are well represented with typical departures between the -40 and the $+40 \mathrm{DU}$ with a clear overestimation. The largest departures are a result of the lack of consideration of the longitudinal ozone variations in the data sets available to the shortwave radiation schemes. Departures between +60 and +80 DU are reached over January and February in a de- 

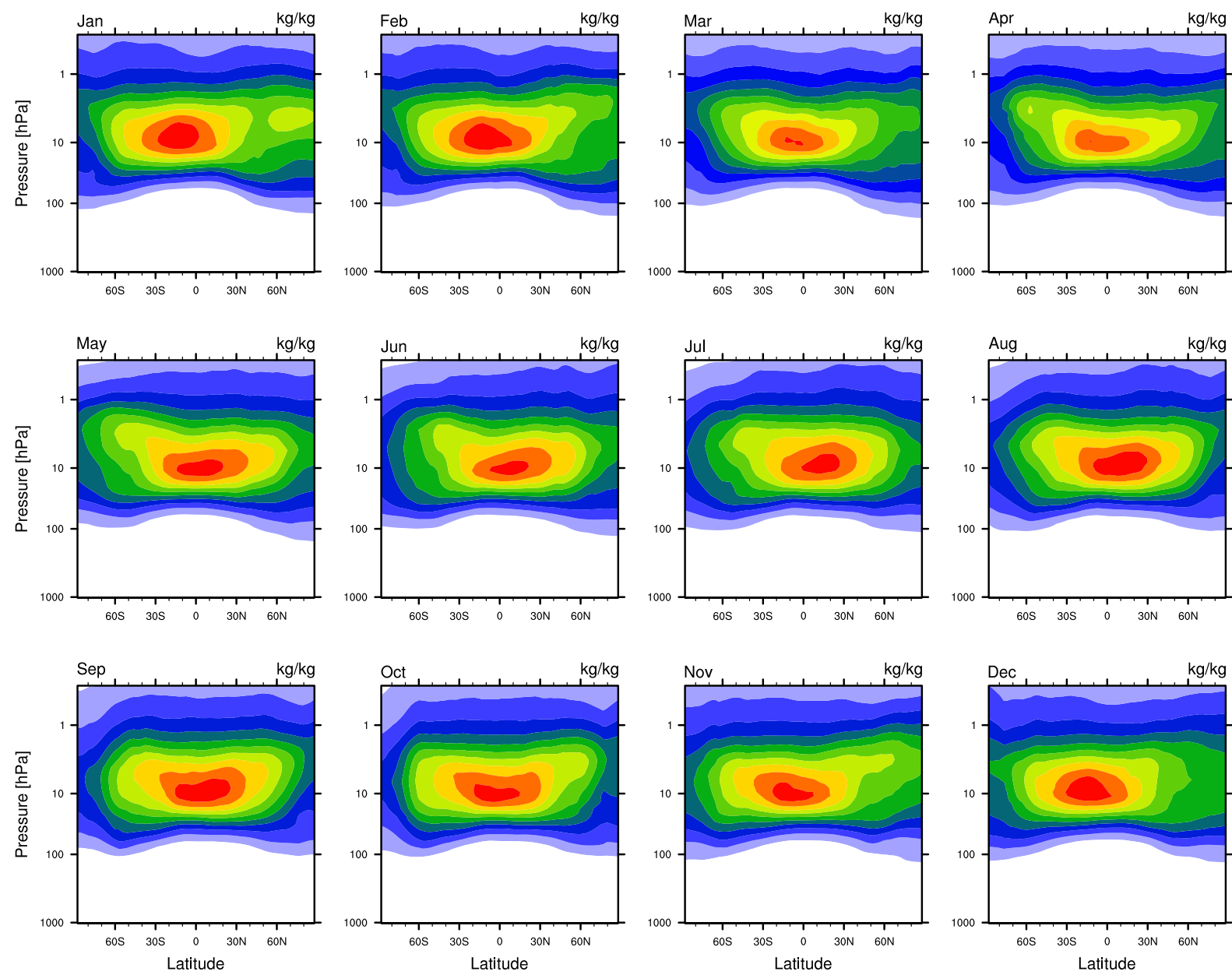

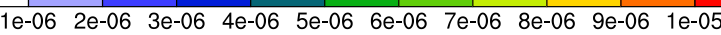

Figure 3. Ozone profile data sets available in CAM.

fined region between Greenland and the Scandinavian Peninsula. Moreover, the east-west variations due to the ozone hole produce a high overestimated region (between +60 and $+80 \mathrm{DU}$ with peaks above $+90 \mathrm{DU})$ around $0^{\circ} \mathrm{E}$ and a high underestimation region ( -60 to $-20 \mathrm{DU})$ in the opposite side of Antarctica (i.e., $180^{\circ} \mathrm{E}$ ). In November and December, an overestimated region $(+0$ to $+20 \mathrm{DU})$ is observed over the Mediterranean Basin and over the Sahara.

Finally, in GFDL scheme (Fig. 7), the total ozone column is slightly underestimated in the tropics and strongly overestimated poleward. The lowest negative biases are observed from December to February ( -20 to $0 \mathrm{DU}$ ) with a maximum at the Equator in a region between Africa and South America ( -60 to -20 DU). During the Northern Hemisphere spring and summer, the negative values increase in magnitude as well as in areas reaching higher latitudes $\left(-50^{\circ} \mathrm{S}\right.$ to $50^{\circ} \mathrm{N}$ ) with peaks reaching $-80 \mathrm{DU}$ at the end of summer. From October to December, this underestimated area is progressively weakened. In mid-latitudes, the pattern dif- fers from the Northern Hemisphere to the Southern. In the first, a dipole between the Atlantic and eastern Asia is observed from December to March. A positive area is observed in the Atlantic region with values from +60 to +100 DU. In contrast, eastern Asia shows negative values from -80 to -40 DU. This pattern is weaker during the Northern Hemisphere spring and fall, disappearing in summer. In the Southern Hemisphere, positive errors are observed without a longitudinal dependency. The lowest biases are produced from January to March (+20 to +100 DU), drifting to higher values from April to December (+80 to +120 DU) during the Southern Hemisphere spring and are maximum in summer and fall reaching peaks greater than +140 DU. The polar regions show a strong seasonal pattern with a positive bias. In both hemispheres, the lowest values are reached in the respective summer while the highest values are produced during the polar night. In the Arctic, the bias is lower than in the Antarctica. From December to February, the Arctic regions reach errors between +100 and +180 DU. In contrast, from 


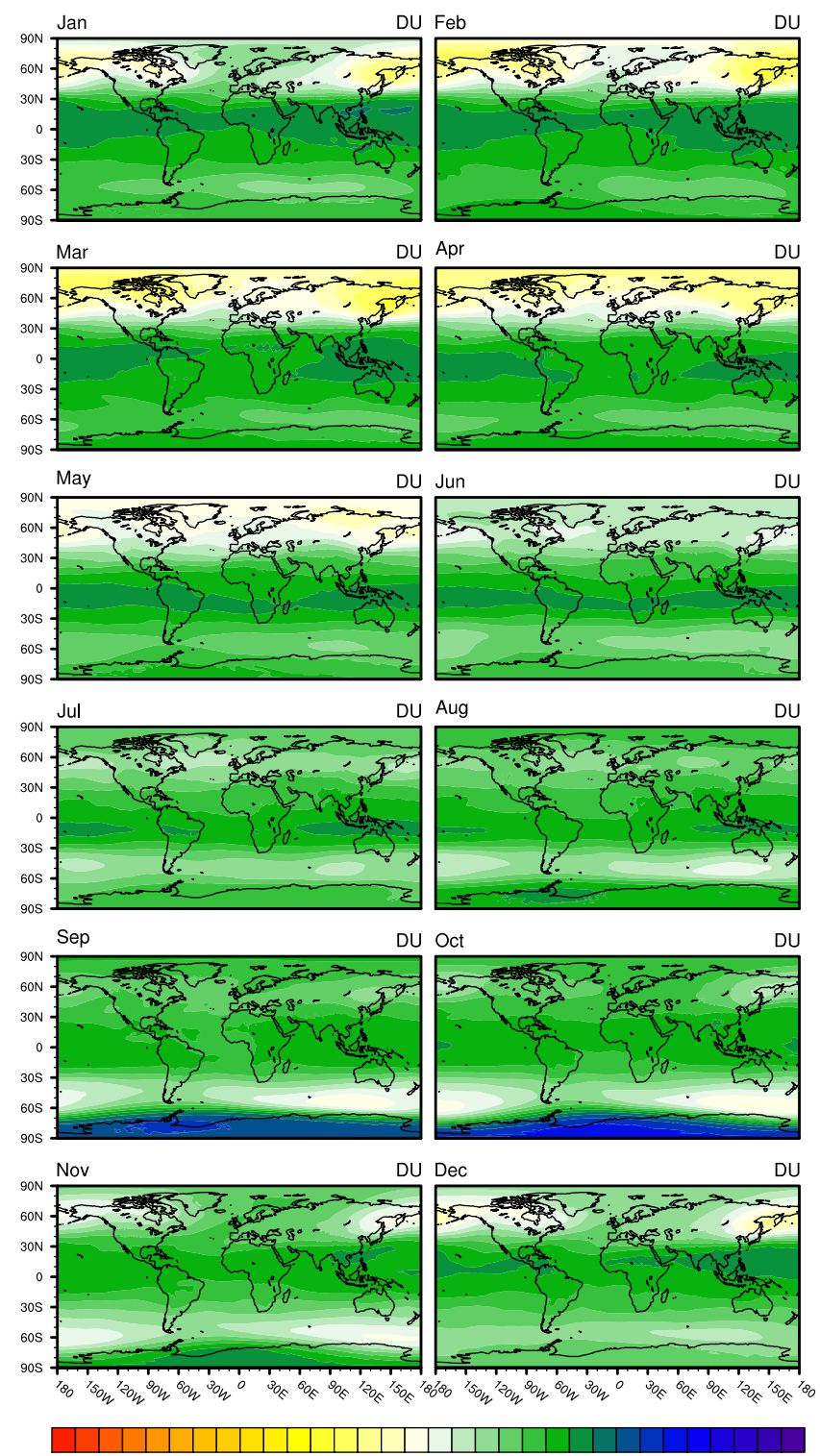

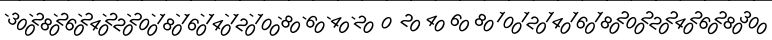

Figure 4. Bias in the total ozone column using the MSR monthly averages for the period (1979-2008) as a baseline for RRTMG.

July to September, the error ranges from +20 to +60 DU. The GFDL scheme has the largest bias of any parameterization over Antarctica from September to October ranging from +280 to $+300 \mathrm{DU}$. The lowest GFDL bias values in Antarctica are experienced during the Southern Hemisphere summer and are larger than those in the Arctic region during its summer.

Latitudinally and seasonally, the distribution of the departures shows a logical coherence with the quality of the ozone profiles available in each shortwave scheme. Thus, the ozone data set in the CAM scheme shows the lowest deviations while the largest global errors are observed in the RRTMG. Generally, the total ozone column is overestimated by all the
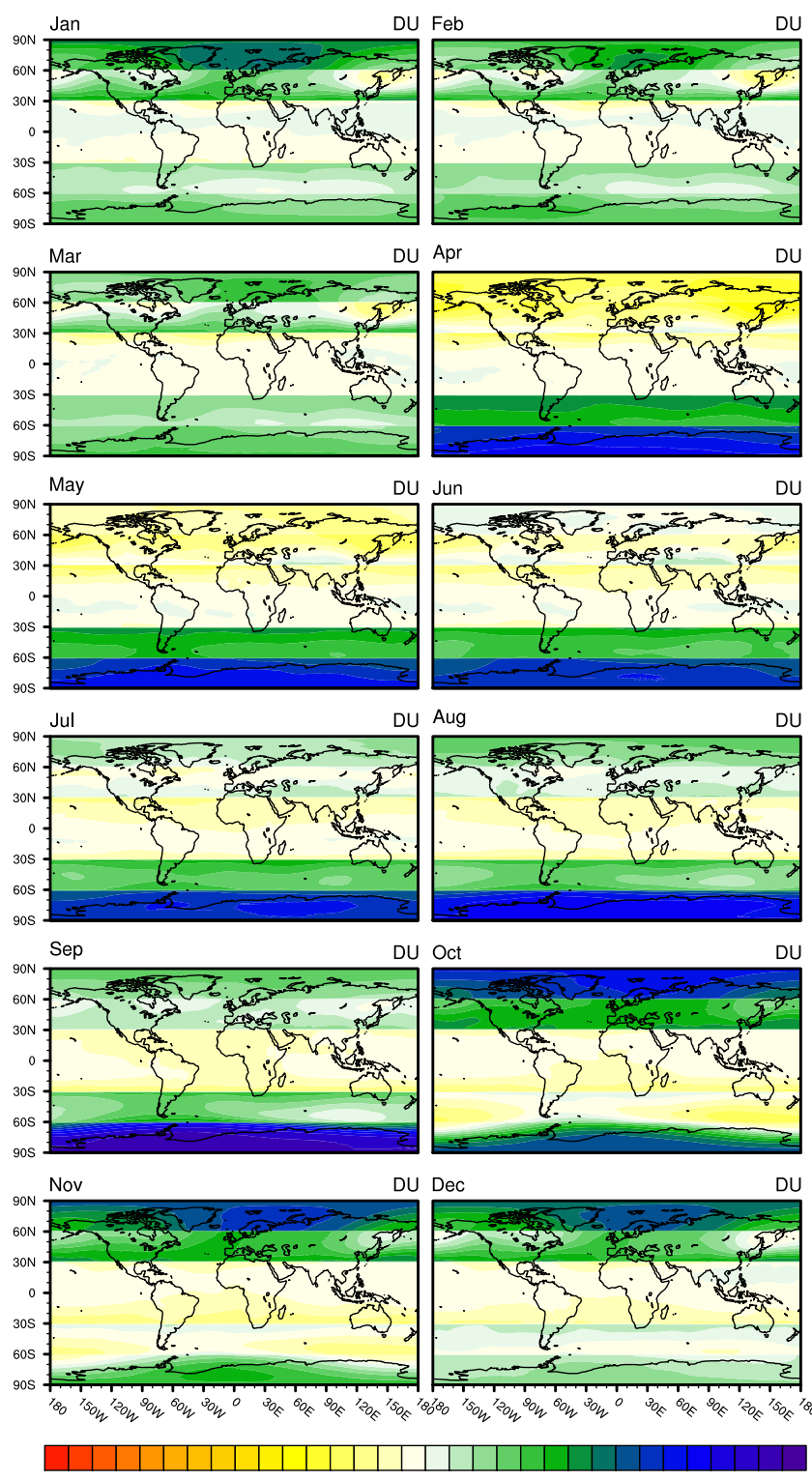

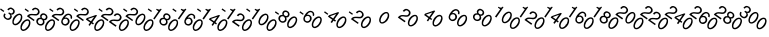

Figure 5. Bias in the total ozone column using the MSR monthly averages for the period (1979-2008) as a baseline for G-NG-FLG.

analyzed schemes with the exception of some locations, especially for the G-NG-FGL profiles. The most extreme departures are observed over Antarctica in late winter and early spring because the ozone hole is too weak in all of the ozone data sets.

Longitudinally, similar distribution patterns can be observed for all the shortwave schemes because all of them assume meridional averages in the ozone mixing ratio. Two zones may be discussed. Firstly, during the Northern Hemisphere fall and winter, an underestimated region is observed between the northeastern side of Asia and the northwestern side of Canada as well as an overestimated region between Greenland and the Scandinavian Peninsula. This pattern re- 

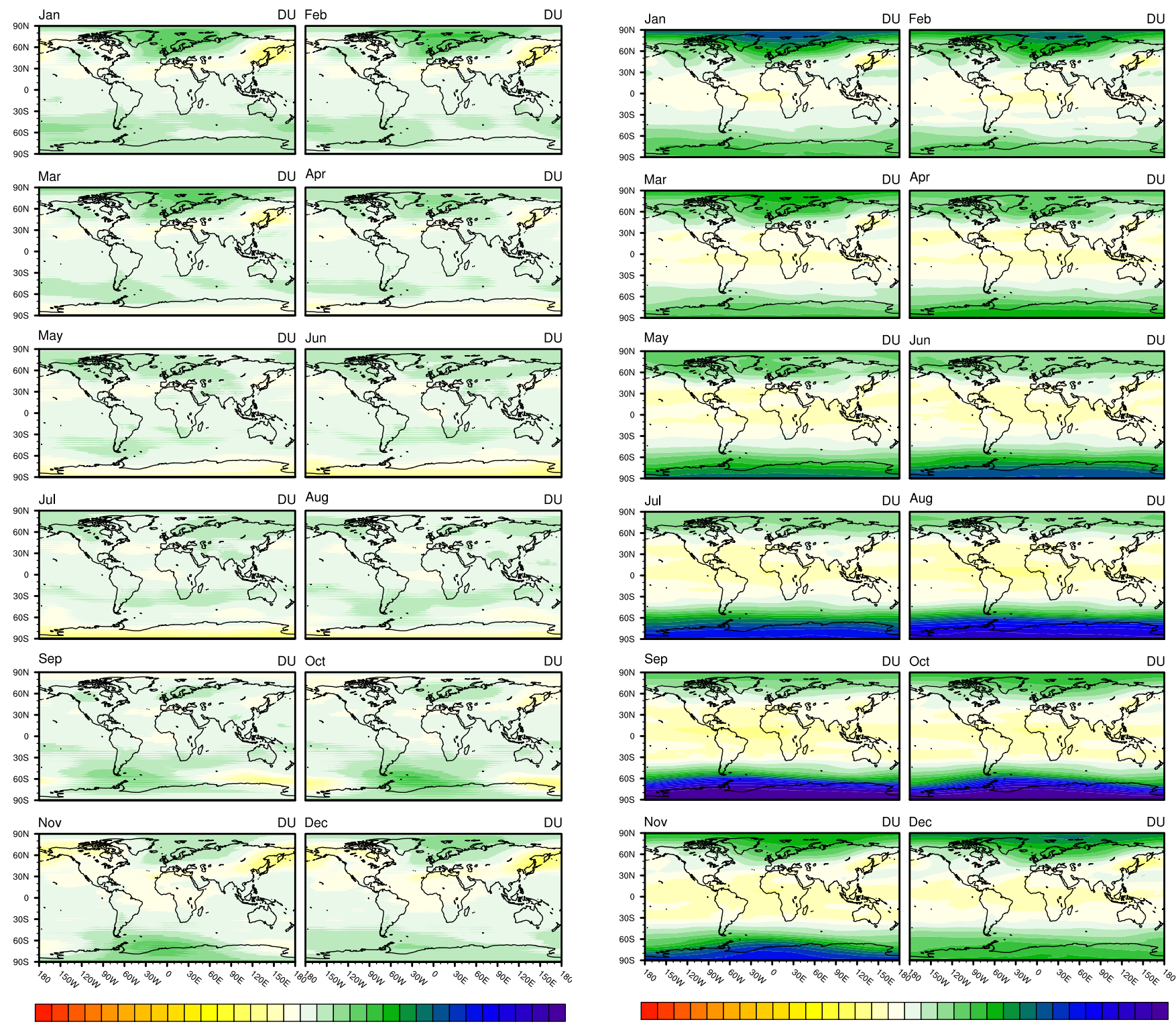

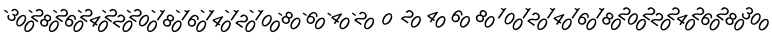

Figure 6. Bias in the total ozone column using the MSR monthly averages for the period (1979-2008) as a baseline for CAM.

flects the quasi-stationary features of the upper-air circulation due to the sea-land distribution in the Northern Hemisphere as discussed in Dütsch (1974) or in Fusco and Salby (1999). Secondly, strong longitudinal gradients in the distribution of the errors are observed over Antarctica due to the ozone hole in September and October. In the other locations, the east-west distribution of the errors may be neglected.

Figure 7. Bias in the total ozone column using the MSR monthly averages for the period (1979-2008) as a baseline for GFDL.

\subsection{Part two: an analysis of the uncertainties added to the computation of the direct solar radiation}

As previously noted in Sect. 2.3, the errors in the specification of the ozone profiles are propagated in the shortwave radiation results. In this section, systematic biases introduced in the modeling of the direct solar radiation are discussed, focusing on three schemes: New Goddard, CAM and GFDL. First, a detailed description of the uncertainties over the globe is shown. Then, a general view of those limitations and their implications is discussed. 
In the New Goddard scheme (Fig. 8), the bias in the total absorption ranges from -3 to $+3 \mathrm{Wm}^{-2}$ reaching peaks near $+6 \mathrm{Wm}^{-2}$ values close to the poles. The absorption is slightly underestimated in the tropics for the entire year. Midlatitude regions show overestimated values in winter, more homogeneous and higher in the Southern Hemisphere than in the Northern, ranging from +0 to $+2 \mathrm{Wm}^{-2}$. Near-zero values are observed over North America and Asia and extended over Europe in March. An exception of this winter pattern occurs over the eastern side of Asia where a bias greater than $-1 \mathrm{Wm}^{-2}$ is observed. During the spring, negative and near-zero departures in the bias are observed over both hemispheres, higher in the Northern (from $-2 \mathrm{Wm}^{-2}$ in April to near-zero values in June) than in the Southern (from slightly negative in October to near-zero in December). In summer, the departures drift from near-zero biases during the early season to positive values at the end of the summer. As in the winter season, the bias is higher in the Southern Hemisphere. The largest negative bias is observed over both hemispheres during the fall, with a peak in the early autumn.

The CAM scheme (Fig. 9) shows the lowest biases in the total absorption of the solar beam due to the ozone. The bias is clearly positive during the whole year with the exception of the northern side of the Pacific Ocean from October to March reaching deviations of $-1 \mathrm{Wm}^{-2}$ in December over the Asian coast and, in some regions over Antarctica from August to October, reaching departures around $-1 \mathrm{Wm}^{-2}$. Two positive maxima are observed, one over the Arctic from January to March with peaks around $+2 \mathrm{Wm}^{-2}$ and, the other over Antarctica from September to November reaching a bias of $+0.5 \mathrm{Wm}^{-2}$. Although this scheme has the highest latitudinal resolution, the largest deviations are observed throughout high-latitudes because the ozone profiles simplify the meridional variations produced by the seasonal ozone depletion that appears from winter until near spring (Southern and Northern Hemisphere).

In GFDL (Fig. 10), absorption biases show a different pattern between the tropics and the other latitudes. In the tropics, the bias is slightly negative throughout the year. The values range from $-3 \mathrm{Wm}^{-2}$ to $0 \mathrm{Wm}^{-2}$. In contrast, the absorption is strongly overestimated in mid-latitudes and polar regions with typical departures between $0 \mathrm{Wm}^{-2}$ and $+5 \mathrm{Wm}^{-2}$. The highest departures are observed over Antarctica from September to November with values between $+6 \mathrm{Wm}^{-2}$ and $+12 \mathrm{Wm}^{-2}$ and in the Arctic from February to April with departures between $+3 \mathrm{Wm}^{-2}$ and $+6 \mathrm{Wm}^{-2}$ being maxima in the Scandinavian Peninsula. Mid-latitude regions show a similar distribution than CAM. Whereas the Southern Hemisphere shows a low dependence on longitude, the Northern shows a pattern with a dependence on space (i.e., meridional) and time. From October to April, two different regions, positive and negative, are observed between the Atlantic and Pacific, respectively. During the other months, the meridional differences are lower and the bias tends to be slightly negative in all latitudes.

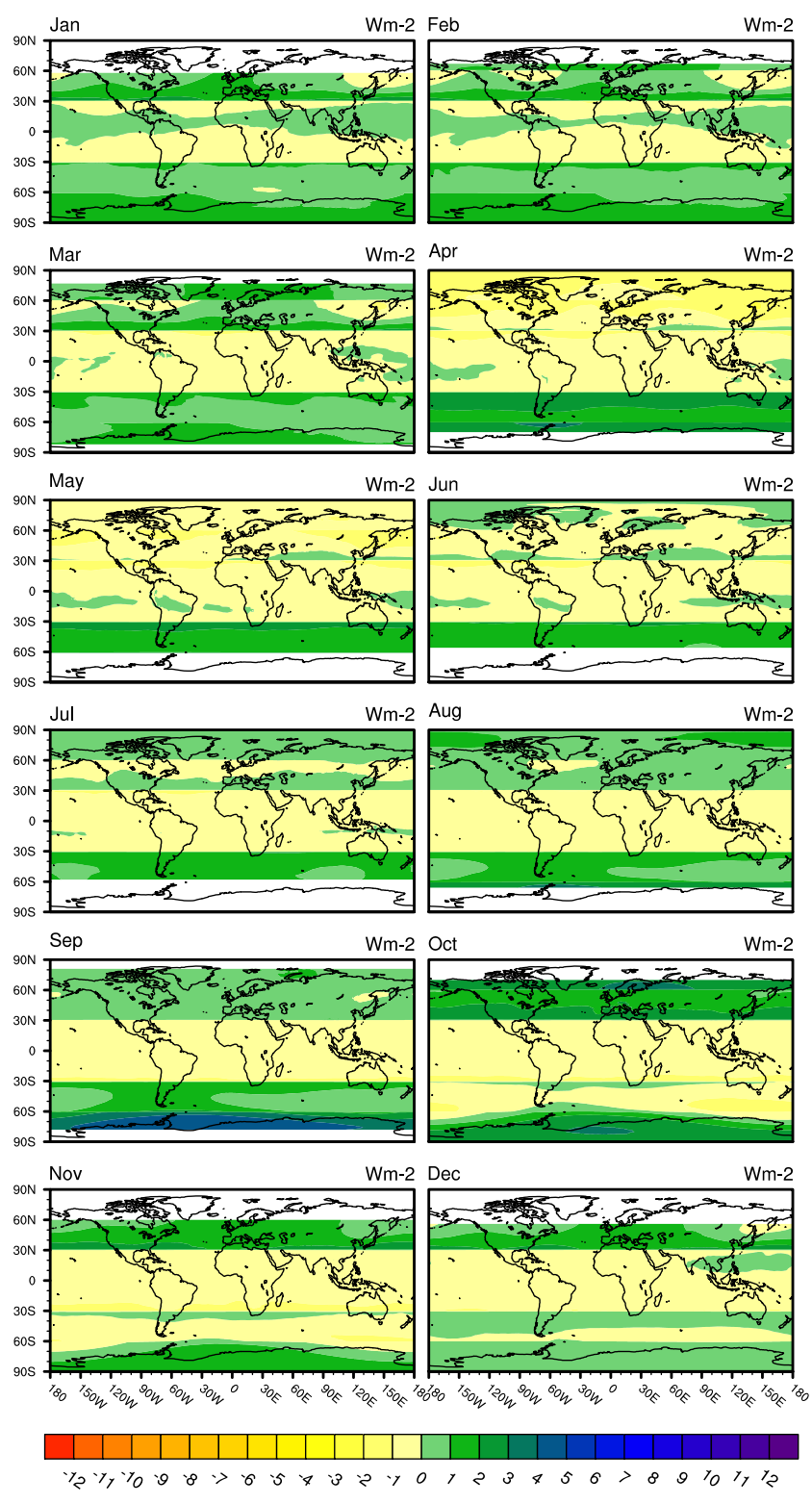

Figure 8. Bias in the ozone absorption using the MSR monthly averages for the period (1979-2008) as a baseline for New Goddard.

The results from this part of the study are generally consistent with the ozone column deviation results shown in Figs. 5, 6 and 7. All the analyzed schemes tend to overestimate the absorption with lower departures in the tropics than in the middle or high latitudes and a maximum over Antarctica during the early Southern Hemisphere spring. As opposed to the results in Sect. 3.1, the impact of these errors on the simulation of the shortwave irradiance at the surface is linked to the solar elevation angle. The highest ozone biases in the poles are masked by their coincidence with the polar night. However, the low solar elevation angles at high latitudes results in a higher sensitivity to the ozone data sets in these latitudes. These factors combine to produce the largest meridional gra- 

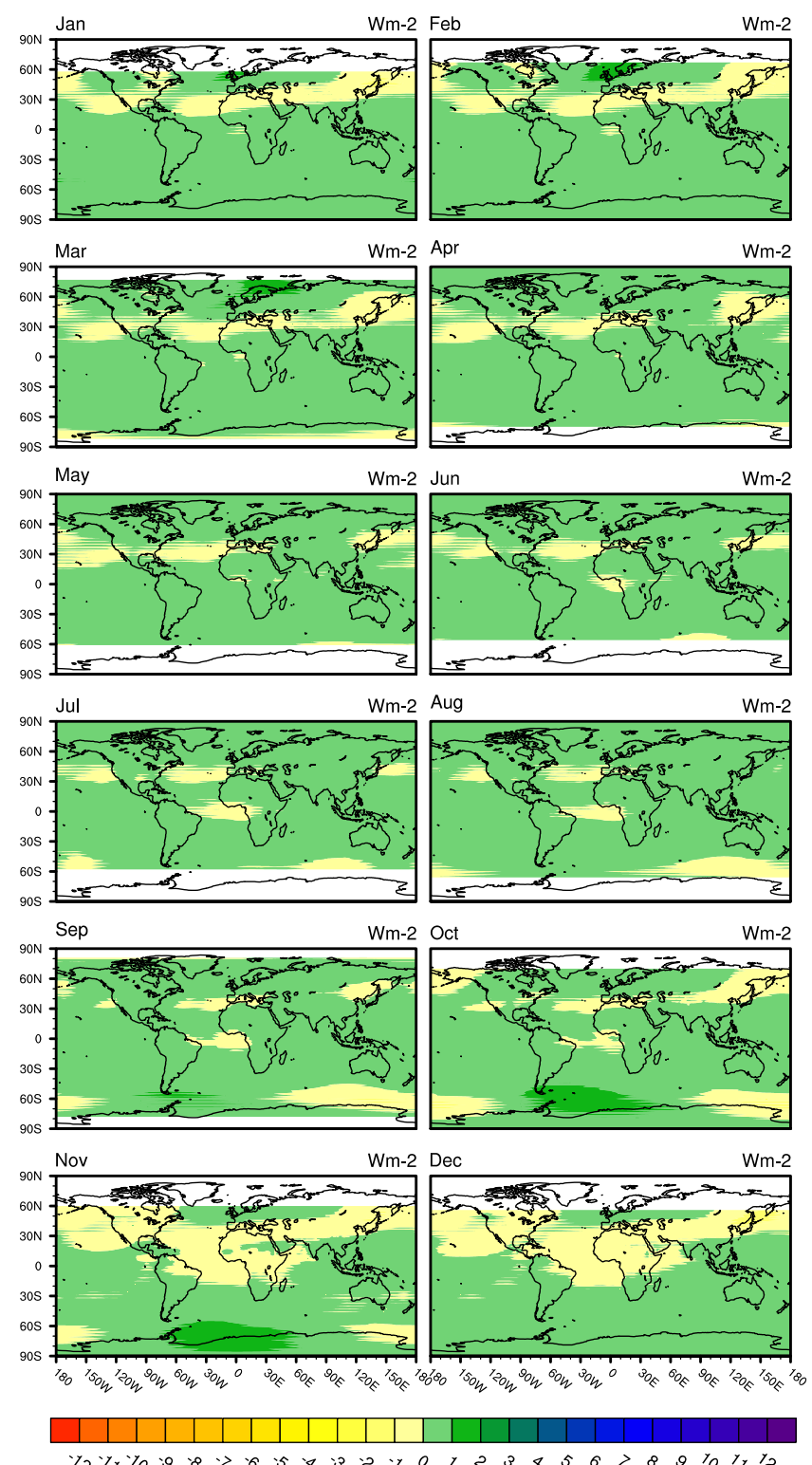

Figure 9. Bias in the ozone absorption using the MSR monthly averages for the period (1979-2008) as a baseline for CAM.

dients in the errors in the modeling of direct solar radiation in the high latitudes during the winter season of each hemisphere.

\section{Conclusions}

Two sets of conclusions can be derived from the results of the analysis presented in this paper. The first set is related to the quality of the ozone concentration data sets available to the WRF-ARW mesoscale model and the second set is associated with the impact of deficiencies in representing the spatial and temporal variations of the ozone profiles on the
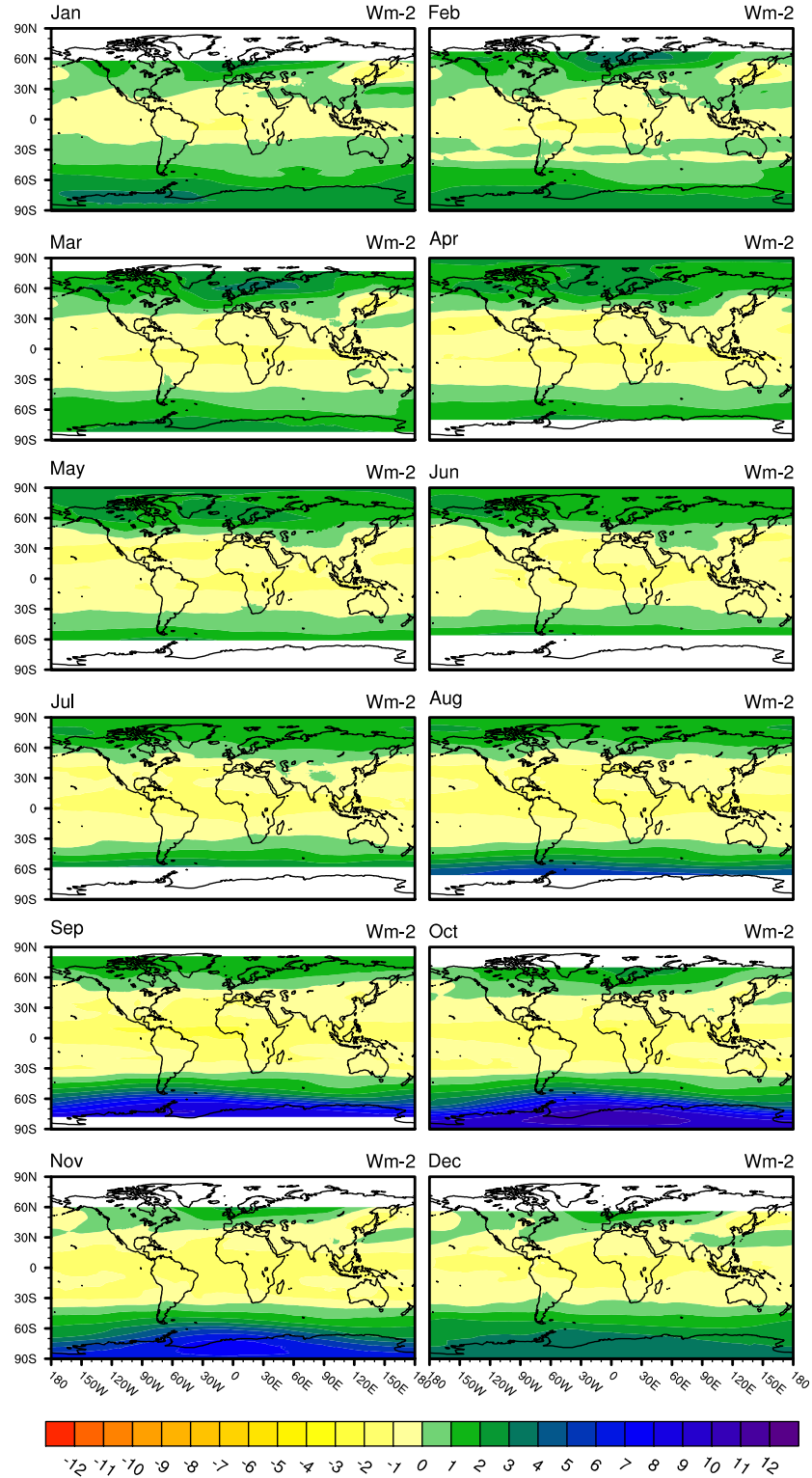

Figure 10. Bias in the ozone absorption using the MSR monthly averages for the period (1979-2008) as a baseline for GFDL.

performance of the shortwave radiation schemes available to WRF-ARW model users.

The key point is that the analysis indicates that the ozone profiles available to the WRF-ARW package are a poor representation of the ozone distribution over the planet during a typical year. These data sets assume zonal averages in the ozone mixing ratio and describe the anomalies in latitude and in time with a low resolution.

In general, the largest deviations are observed over the polar latitudes during the winter of each hemisphere due to the ozone depletion, greater in Antarctica than in the Arctic.

All the WRF-ARW ozone data sets that were analyzed in this study exhibited similar longitudinal error patterns. The 
error patterns were more prominent in the Northern Hemisphere due to the quasi-stationary features associated with the land-sea distribution that are not captured in the ozone profiles. As a consequence, a systematic underestimation of the total ozone column is observed in a region between the east of Asia (i.e., eastern Russia) and the west of North America (i.e., Alaska and western Canada) during the Northern Hemisphere winter and near spring. In contrast, a systematic overestimation occurs in a region defined between Greenland and the Scandinavian Peninsula during the Southern Hemisphere fall and near winter.

The RRTMG, with a single ozone profile for all the latitudes and seasons, is the shortwave scheme with the poorest ozone resolution and the largest departures relative to the climatology. Only the mid-latitudes in the Northern Hemisphere show small deviations for being calibrated in these latitudes.

The ozone profiles used by the Goddard, New Goddard and the $\mathrm{Fu}-\mathrm{Liou}-\mathrm{Gu}$ consider five ozone profiles: tropical, mid-latitude (winter/summer) and Arctic (winter/summer) for both hemispheres. This discretization shows better results in the Northern Hemisphere than in the Southern Hemisphere. The tropical profile shows a systematic underestimation of the ozone amount over any longitude, greater in the summer hemisphere, near-zero in the winter hemisphere and practically homogeneous during the equinoxes. This underestimation pattern is directly linked to the obliquity of the ecliptic and the available insolation producing more ozone in summer than in winter. Positive departures are observed over the mid-latitudes in winter and summer, better for the second one in both hemispheres. Negative deviations are observed during spring while the worst results of the year are obtained during fall. A similar pattern is observed in the polar regions with greater differences between the northern and the southern as discussed at the beginning of this section.

Finally, the CAM shortwave parameterization shows the lowest departures in the total ozone column. This scheme, composed of 64 ozone profiles with a monthly temporal resolution, captures a large part of the ozone variations over the globe. The largest deviations are observed throughout the longitudes because of the zonal averages in the profile data sets. The highest zonal gradients in the errors are observed over the poles during the winter season of each hemisphere.

The second set of conclusions addresses the impact of the deficiencies in the specification of the ozone distribution on the simulation of the shortwave radiation. A key point is that the impact of errors in the representation of the spatial and temporal distribution of ozone on the model's simulation of shortwave radiation is determined by multiple factors and it is not a simple function of the errors in the ozone profiles. For example, the largest errors in the ozone profiles were determined to be in the polar regions during winter. However, the impact of these errors on the simulation of shortwave radiation are masked by the coincidence of these errors with the polar night. On the other hand, the low solar ele- vation angles at high latitudes result in a higher sensitivity of the shortwave radiation schemes to the ozone profiles in these latitudes. These factors combine to produce the largest meridional gradients in the errors in the simulations of shortwave radiation in the high latitudes during the winter season of each hemisphere.

The lowest biases in the absorption of the solar direct beam occur over the tropics (Figs. 8, 9, 10) with near-zero departures. In contrast, the largest biases are observed poleward during the winter of each hemisphere. Longitudinally, the underestimated ozone region over the northern Pacific produces important biases in the absorption.

The CAM parameterization shows lower biases $(-1$ to $\left.1 \mathrm{Wm}^{-2}\right)$ than the New Goddard scheme $\left(-3\right.$ to $\left.3 \mathrm{Wm}^{-2}\right)$ and GFDL ( -2 to $2 \mathrm{Wm}^{-2}$ ) with the same spatial and temporal distribution found in the total ozone errors as expected.

The greatest overestimation for all schemes is over Antarctica during the September-November period. The GFDL is the worst parameterization in this situation $\left(8\right.$ to $12 \mathrm{Wm}^{-2}$ ) followed by New Goddard ( 1 to $5 \mathrm{Wm}^{-2}$ ) and then CAM (0 to $1 \mathrm{Wm}^{-2}$ ).

In conclusion, the ozone profiles provided with the WRFARW package have significant limitations because of their simplified representation of spatial and temporal variability of ozone concentrations. These limitations introduce systematic biases in the modeling of shortwave radiation at the surface that can be easily reduced with more sophisticated data sets. The results of this study suggest that there would be value in having a reference ozone climatology that is dependent on the month and longitude and in a format that could be used by all of the radiation schemes in the WRF-ARW model. However, there is a substantial obstacle that must be overcome to achieve this objective. This is the fact that most of the global climatology data sets (e.g., MSR) are vertically integrated and the other sources of data (e.g., Binary Data Base of Profiles (Bodeker and Hassler, 2012)) provide latitude and vertical profiles without considering the longitudinal dependence, such as in the data sets used in the CAM parameterization. Therefore, the performed improvement made since version 3.5 (Sect. 2.1), which enables the RRTMG scheme to utilize the ozone profiles available in CAM, should be extended to the other solar parameterizations.

In view of the conclusions presented in this paper, a future study of the daily variation in the deviations could be valuable for solar short-term forecasting, since introduced biases could be corrected by using different statistical postprocessing approaches (e.g., model output statistics, MOS). Furthermore, the ozone profiles could be validated using real ozone soundings in order to determine the impact of deficiencies in the vertical profiles on the calculation of the vertical profile of the solar heating rate, which is important for the modeling of stratospheric processes. 
Acknowledgements. The research leading to these results received funding from the Departament d'Economia i Coneixement de la Generalitat de Catalunya in the frame of the Talent Empresa programme (grant: 2010-TEM-49).

Edited by: J.-Y. Christine Chiu

\section{References}

Anderson, S. M. and Mauersberger, K.: Laser measurements of ozone absorption cross sections in the Chappuis band, J. Geophys. Res. Lett., 19, 933-936, doi:10.1029/92GL00780, 1992.

Bodeker, G. and Hassler, B.: Bodeker Scientific Global Vertically Resolved Ozone Database, (Internet), NCAS British Atmospheric Data Centre, 2012, 201412-04, available at: http://catalogue.ceda.ac.uk/uuid/ 9a2438602c2b534f54d81e54b9d98d75, 2012.

Brewer, A.: Evidence for a world circulation provided by the measurements of helium and water vapour distribution in the stratosphere, Q. J. Roy. Meteor. Soc., 75, 351-363, 1949.

Briegleb, B. P.: Delta-Eddington approximation for solar radiation in the NCAR Community Climate Model, J. Geophys. Res., 97, 7603-7612, 1992.

Chandrasekhar, S.: Radiative Transfer, Dover Publications, New York, 1960.

Chou, M.-D. and Suarez, M. J.: An efficient thermal infrared radiation parameterization for use in general circulation models, NASA Tech. Memo, NASA/GSFC, 104606, 3, 1994.

Chou, M.-D. and Suarez, M. J.: A Solar Radiation Parameterization for Atmospheric Studies, NASA Tech. Memo, NASA/GSFC, 104606, 40, 1999.

Chou, M.-D., Suarez, M. J., Liang, X.-Z., and Yan, M. M.-H.: A thermal infrared radiation parameterization for atmospheric studies, NASA Tech. Memo, 104606, 56, available at: http:// ntrs.nasa.gov/search.jsp?R=20010072848 (last access: 1 August 2014), 2001.

Collins, W. D., Rasch, P. J., Boville, B. A., Hack, J. J., McCaa, J. R., Williamson, D. L., Kiehl, J. T., Briegleb, B., Bitz, C., Lin, S., Zhang, M., and Dai, Y.: Description of the NCAR Community Atmosphere Model (CAM 3.0), NCAR Tech. Note NCAR/TN464+ STR, Boulder, Colorado, 2004.

Dee, D. P., Uppala, S. M., Simmons, A. J., Berrisford, P., Poli, P., Kobayashi, S., Andrae, U., Balmaseda, M. A., Balsamo, G.,Bauer, P., Bechtold, P., Beljaars, A. C. M., Berg, L., Bidlot, J., Bormann, N., Delsol, C., Dragani, R., Fuentes, M., Geer, A. J., Haimberger, L., Healy, S. B., Hersbach, H., Hólm, E. V., Isaksen, L., Kållberg, P., Köhler, M., Matricardi, M.,McNally, A. P., Monge-Sanz, B. M., Morcrette, J.-J., Park, B.-K., Peubey, C., Rosnay, P., Tavolato, C., Thépaut, J.-N., and Vitart, F.: The ERA-Interim reanalysis: configuration and performance of the data assimilation system, Q. J. Roy. Meteor. Soc., 137, 553-597, doi:10.1002/qj.828, 2011.

Dobson, G. M.: Origin and distribution of the polyatomic molecules in the atmosphere, Proc. R. Soc. Lon. Ser.A, 236, 187-193, 1956.

Dudhia, J.: Numerical study of convection observed during the winter monsoon experiment using a mesoscale two-dimensional model, J. Atmos. Sci., 46, 3077-3107, doi:10.1175/15200469(1989)046<3077:NSOCOD>2.0.CO;2, 1989.
Dudhia, J.: A history of mesoscale model development, Asia-Pac. J. Atmos. Sci., 50, 121-131, doi:10.1007/s13143-014-0031-8, 2014.

Dütsch, H.: The ozone distribution in the atmosphere, Can. J. Chem., 52, 1491-1504, 1974.

Fels, S. and Schwarzkopf, M.: An efficient, accurate algorithm for calculating CO2 $15 \mu \mathrm{m}$ band cooling rates, J. Geophys. Res., 86, C2, 1205-1232, 1981.

$\mathrm{Fu}$, Q. and Liou, K., N.: On the correlated k-distribution method for radiative transfer in nonhomogeneous atmospheres, 49, 22, 2139-2156, doi:10.1175/15200469(1992)049<2139:OTCDMF>2.0.CO;2, 1992.

Fusco, A. and Salby, M.: Interannual variations of total ozone and their relationship to variations of planetary wave activity, J. Climate, 12, 1619-1629, 1999.

Gu, Y., Liou, K., Ou, S., and Fovell, R.: Cirrus cloud simulations using WRF with improved radiation parameterization and increased vertical resolution, J. Geophys. Res., 116, D06119, doi:10.1029/2010JD014574, 2011.

Iacono, M. J., Delamere, J. S., Mlawer, E. J., Shephard, M. W, Clough, S. A. and Collins, W. D.: Radiative forcing by long lived greenhouse gases: Calculations with the AER radiative transfer models, J. Geophys. Res., 113, D13103, doi:10.1029/2008JD009944, 2008.

Inn, E. C. and Tanaka, Y.: Absorption coefficient of ozone in the ultraviolet and visible regions, J. Opt. Soc. Am., 43, 10, 870$872,1953$.

Kim, H. J. and Wang, B.: Sensitivity of the WRF model simulation of the East Asian summer monsoon in 1993 to shortwave radiation schemes and ozone absorption, Asia-Pac. J. Atmos. Sci., 47, 2, 167-180, 2011

Lacis, A. A. and Hansen, J.: A parameterization for the absorption of solar radiation in the Earth's atmosphere, J. Atmos. Sci., 31, 118-133, 1974.

Liou, K. N.: An Introduction to Atmospheric Radiation, Vol. 84, International Geophysics Series, Academic Press, New York, 1980.

NOAA: US Standard Atmosphere, 1976, Tech. rep., NOAA-S/T, U.S. Government Printing Office, Washington, D.C., 1976.

Ramanathan, V. and Dickinson, R. E.: The Role of Stratospheric Ozone in the Zonal and Seasonal Radiative Energy Balance of the Earth-Troposphere System, J. Atmos. Sci., 36, 1084-1104, 1979.

Rodgers, C. and Dickinson, R. E.: The radiative heat budget of the troposphere and lower stratosphere, Planetary Circulation Project, Rep, A2, 1967.

Ruiz-Arias, J. A., Dudhia, J., Santos-Alamillos, F. J. and Pozo-Vázquez, D.: Surface clear-sky shortwave radiative closure intercomparisons in the Weather Research and Forecasting model, J. Geophys. Res. Atmos., 118, 9901-9913, doi:10.1002/jgrd.50778, 2013.

van $\operatorname{der}$ A, R. J., Allaart, M. A. F., and Eskes, H. J.: Multi sensor reanalysis of total ozone, Atmos. Chem. Phys., 10, 11277-11294, doi:10.5194/acp-10-11277-2010, 2010.

WMO: Atmospheric Ozone, Tech. Rep. 16, Global Ozone Research and Monitoring Project, Geneva, 1986.

WMO: Scientific Assessment of Ozone Depletion: 2010, Tech. Rep. 16, Global Ozone Research and Monitoring Project, Geneva, 2011. 